\title{
Domesticating Animals: A Description of a Certain Disturbance
}

Szymon Wróbel 
Szymon Wróbel

\section{Domesticating Animals: A Description of a Certain Disturbance}

DOI: 10.18318/td.2015.en.1.16

\section{Breeding}

Sigmund Freud, in a significant chapter of Totem and Taboo entitled The Infantile Recurrence of Totemism analyzes a child's particular relationship towards animals. Freud suggests that the child does not display pride which is characteristic for an adult and requires one to make a sharp distinction between one's own nature and the nature of an animal. The sense of superiority of the adult human towards the animal is alien to the child and results from a long process of breeding for this "superiority", which will have the consequence of the sense of absolute loneliness and eccentricity of the human kind in nature. Initially, the child recognizes animals as his equals without hesitation - what is more, the child feels a greater connection with animals than with the adults, whom he perceives - as Freud writes - as "mysterious". The mysteriousness of the adult world is supposedly emphasized by the children's feeling of belonging to the world of animals, which seems to be closer and more familiar to them than the world of intelligent consequences of civilized people. The experienced kinship with the animal kingdom is therefore the other side of the still very uneasily felt alienation from the world of humanity. Over time, the alienation will swap places with familiarity: what is
Szymon Wróbel

- psychologist and philosopher, professor in the Artes Liberales Department of UW and professor in IFiS PAN. His two recent books include Deferring the Self published in 2013 by Peter Lang Verlag and Lektury retroaktywne. Rodowody współczesnej myśli filozoficznej (2014). Contact:wrobelsz@ gmail.com 
familiar will become absolutely alien, and what is alien will become absolutely familiar. I call this displacement of what is familiar and what is alien the process of "domestication"; in consequence, the "animal" becomes the representative of the domesticated regime of culture.

This essay is about the process of "domestication", which was the beginning of breeding of both diverse species of animals and of the human species itself. However, because domestication is always the domestication of something for someone, strangeness and familiarity, mysteriousness and commonness, attachment and rejection, rooting and uprooting, they all constitute concepts which tend to shift positions rather than permanently define "objects" (human and animals) and the specific regions of reality (house or nature). Friedrich Nietzsche, in the seventh chapter of his Twilight of the Idols makes an excellent diagnosis of the process of "domestication" and its consequences, stating that the use for morality can assume two opposite forms. An improvement, writes Nietzsche, is what we call both the taming of the beast, i.e. breeding a "human" and perhaps even a "superhuman", and the breeding of a particular species of a "human" - the docile, domesticated, deceptive, reactionary, and "inactive"1. Nietzsche cautions that the morality of breeding and the morality of domesticating match each other completely in the selection of means by which they can ensure their victory. Yet raising and breeding are identical in their selection of goals and in the effects of their actions. The effect of breeding in a human is a hundredfold more gentle and more rational than in the case of the "improvement" performed by a priest. The goal of breeding understood as an ascetic regime is not a person's "self-control", although in the case of "domesticating" (raising) we are dealing with exclusion - but it is not the exclusion of the beast from the human, but the exclusion from society of a group of beings, sub-humans, Tschandalas, identified with the illness, and as a result not included in the human race.

In this text, mainly by reading texts by Freud, Lévi-Strauss and Kafka, I would like to consider this intriguing difference between "breeding" and "domesticating" (raising), the difference between an Übermensch and a pseudo-human, a sick human and a human in full health, a human cross-bred with other species (beetle, spider, bat) and a human dramatically guarding his genetically pure humanity. I would like to enquire if humanity, empowered by kinship or even contamination with other species, and multiplied by other species, not only - to use Donna Haraway's expression - companion species²,

1 Friedrich Nietzsche, Twilight of the Idols, trans. Duncan Large (Oxford: Oxford University Press 1998).

2 Donna Haraway, The Companion Species Manifesto: Dogs, People, and Significant Otherness (Chicago: Prickly Paradigm Press, 2003). 
would be a society which is sick, frail and ill-selected, or whether it would rather be a humanity which is active and audacious, looking for adventure, devoid of traces of resentment towards other living beings, and as a result the only one which is acceptable in the contemporary world?

\section{Disturbance}

The condition of unity and full kinship with the world of animals does not last long in a child's life. Freud claims that between a child and an animal there appears a certain "disturbance" at one stage. "The child", writes Freud, "suddenly begins to fear a certain animal species and to protect himself against seeing or touching any individual of this species. There results a clinical picture of an animal phobia, which is one of the most frequent among the psychoneurotic diseases of this age and perhaps the earliest form of such an ailment"3. The child's phobia begins to apply to the animal which used to fascinate him, but since the choice of a specially marked animal in the city (a closed, territorial space) is limited to a few species - birds, dogs, horses, and as Freud writes "very small animals like bugs and butterflies", phobias have a range which is very predictable and limited in content. According to Freud, this restriction of content (i.e. the representational poverty of our fears) is also the poverty of the mechanism or the fundamental motive causing fear, which always proves to be the fear of the father. The Father in this affective economy constitutes the object shifted to the position of the animal. In Freud, the animal always refers us back to the Father, whereby the totemic animal and the name of the Father refer to the name of the totem and also the rights of the Father. The fusion of the animal and the father gives the position of God.

In his already famous text entitled Analysis of the Phobia of a Five-Year-Old Boy which related fears of the little Hans ${ }^{4}$, Freud goes in a similar direction, allowing for the unification of three elements: totem, father, and name (God). Hans not only feared horses but also initially held them in respect mixed with fascination. Similarly to totemic tribes, Hans not only feared animals of one species but also treated them with utmost respect. What is important for this economy of affects and dealing with affects is the fact that when Hans overcame his fear he identified himself with the animal to such a degree that he started to jump like a horse and neigh like a horse, eventually becoming

3 Sigmund Freud, Totem and Taboo: Resemblances Between the Psychic Lives of Savages and Neurotics, trans. A. A. Brill, (New York: Moffat, Yard \& Co. 2010), http://www.bartleby.com/br/281. html 
a creature which "bit the father". What is important, Hans identified his parents with other large animals, therefore introducing in the space of his imagination his whole family and the world which surrounded him. One could state that Hans overcame the mystery of the world of adults through its naturalization, i.e. the introduction of a false transcendence of culture and that which is social into a space of immanence of his "own nature". Personal fantasies on the subject of nature helped little Hans to neutralize the fears concerning the adult fantasies on the subject of nature.

A similar transformation of human to animal is experienced by little Arpad, cited by Freud and analyzed by Sándor Ferenczi; during his vacation, the three-year-old boy was pecked at the penis by a chicken while he urinated and as a result "he himself turned into a fowl". After this episode Arpad started to get interested in the fowl-house population to such a degree that he abandoned the human tongue, started to cackle and crow, and when he used human speech it was solely to spin yarns of chickens and other fowl. However, his behavior towards the marked animal was full of ambivalence and was expressed in an excessive, simultaneous hate and love towards chickens. Arpad adored chickens, but also his favorite game was to play at killing chickens. To him, slaughtering fowl was the greatest of holidays. Perhaps it is worth noting that when Freud describes Hans he uses the word "identification" with the horse, but when he describes little Arpad's case, he says that the child "himself turned into a fowl". This difference between "identification with the animal" and "turning into an animal" may prove to be symptomatic and crucial for our differentiation between "breeding" and "domestication". Perhaps the identification will prove to be a consequence of the raising (domestication) whereby turning into an animal will be strictly connected with the process of breeding. It may be important that to Freud a "holiday is permitted, or rather a prescribed excess, a solemn violation of a prohibition"5. Freud, therefore, talks about the necessity of a holiday, but not about the right to celebrate or the possibility of celebration. Hence, for Freud there exists a compulsion of transgression, which is a holiday.

I would like to enquire if today we are not living a world which already is a constant compulsion of transgression, and therefore a world of a neverending holiday? The modern man's holiday is above all the transgression of borders of his closed humanity, it is a command to be something more than just a human. Nietzsche's Übermensch as a blond-haired beast is nothing other than a fantasy of a gregarious human, who "became a resentful chicken", incapable of affirmation, and desiring to abolish his decadent alienation through male fantasies of a new leader, capable of "biting the father" - Batman

5 Freud, Totem and Taboo. 
or Superman. Breeding, especially ancient (ascetic) breeding could only have happened at the price of the emergence of the subject, which through its exclusion established a society of humans: improved and superior. Breeding in the time of mass democracy (raising) reverses those proportions - throngs of gregarious beings are to enable the breeding of a few tyrants, who also become their own creators - replicants. Science and biotechnologies are solely to help in realization of this intention. I ask, therefore, whether little Hans, analyzed by Freud, and Arpad, diagnosed by Ferenczi, announce the coming of this era of Batmen and Spidermen, an era of horse-men, chicken-men, who will become the tyrants of the new breeding and of the new domestication?

\section{Totem}

Freud, who analysed the relationship of children towards animals and the genesis of the children's neuroses, formulated a thesis of an infantile return of totemism. Totemism and children's neuroses have a trait in common: the totemic animal is called a father (ancestor) and the father is referred to by the name of the totemic animal (horse, chicken, etc.). "If the totem animal is the father", claims Freud, "then the two principal ordinances of totemism, the two taboo prohibitions which constitute its core - not to kill the totem and not to have sexual relations with a woman of the same totem - coincide in their content with the two crimes of Oedipus, who killed his father and married his mother, as well as with the two primal wishes of children, the insufficient repression or the re-awakening of which forms the nucleus of perhaps every psychoneurosis"6. According to Freud, the totemic system stems from the conditions causing the Oedipus complex, just like "little Hans" fear of the horse and little Arpad's perversion. What does it mean?

Oedipus's structure establishes both the rule of integration of the totemic system, which simultaneously wants to disclose and conceal the connection between the clan and the given totemic animal, as well as the structure of neurosis, which wants to simultaneously disclose and conceal its kinship to love and hate towards the father. Freud is aware of the power of his generalization but he does not avoid it and it seems that the analogy between a totemic human and the "little Hans", as well as the even smaller human, Arpad, looking for his kinship with animals: horses or chickens, is attracted not only as the model of any and all identification, but also as the model of any human psychic achievement. This achievement is connected above all with the establishment of rules of kinship and rules of culinary art, allowing for the making of a distinction of the permitted objects of desire from the prohibited, and

6 Ibid. 
the edible from the inedible. This methodological stance of Freud's requires that we nonetheless ask the following question: what is a totemic animal and what does it have to do with the animal which is the object of our childhood phobias? Moreover, we should ask if the totemic animal and religious rituals come together and interconnect in our ambivalent affects for the father? Are God and the totemic animal just masks and disguises of the Father?

Freud writes about the domesticated and non-domesticated animals, small and large, herbivores and carnivores, water and land animals, mammals and insects, sacred animals and animals present in mundane experiences, sanctified by sacrifice and "merely" edible, but he always writes as if the animals were a constant source of human fascination. "Such animals as birds, snakes, lizards, mice", we read in Totem and Taboo, "are fitted by their extreme mobility, their flight through the air, and by other characteristics which arouse surprise and fear, to become the bearers of souls which leave their bodies. The totem animal is a descendant of the animal transformations of the spiritsoul"7. Let us repeat what Freud said, to hear his voice better and more clearly: animals are fit to be considered carriers of the souls which have left bodies. If so, one should ask further: who does the animal have to be, to become the vessel for the human soul, which has left its body? Who does that animal have to be, to be endowed with the power to shape our thinking and our imagination? And, in this animistic interpretation of totemism and neurosis, does Freud not cause a certain conflict of interpretation between the ideology of the Oedipus complex, in which the Father is the strongest element structuring religion, totemism and neurosis, and animal ideology, in which the totemic animal is the ur-motive incorporating the powers of the Name of the Father and God the Father, who are solely the incarnations of the Totemic Animal?

Originally, totems were animals and were regarded as ancestors of particular tribes. Totemic animals did not just constitute the name of the group members of a particular tribe, but they became the controllers of relationships of kinship and consumption. Humans grouped around the totem formed a production and consumer relationship: because the clan could not consume the given totem it supplied a valuable product to other totems and was in turn supplied with what the other totems took care of as a part of their duties. The situation was similar with kinship. The totem establishes the law, according to which the members of the same totem could not engage in sexual intercourse, and thus enter into marriage. If, for instance, a man from the Kangura (Horse) clan takes for his wife a woman from the Emu (Chicken) clan, their children will all be Emu (Chickens), regardless of their sex. The totemic rule

7 Freud, Totem and Taboo. 
prevents the son from such a marriage from initiating sexual relations with his mother and sisters, who like him are Emu (Chickens).

Perhaps partly a new light on all those ambiguities formulated and abandoned by Freud in The Infantile Recurrence of Totemism could be shed by the analyses of Claude Lévi-Strauss in his memorable chapter of The Savage Mind entitled The Individual as a Species ${ }^{\mathbf{8}}$, which returns to Freud's narration and talks about the infantile return of totemism under the guise of its humanizing.

In this chapter Lévi-Strauss seems to be intrigued not only by the forms of classification; his thought is not only provoked by the levels of abstraction and concretization of the "savage mind" and the complex relations between the species and the individual, but above all, Lévi-Strauss is interested in the proper names (necronyms and autonyms) and a constant presence of the forms of totemic thinking in the contemporary world, which culminates in the statement: "Everything takes place as if in our civilization every individual's own personality were his totem"9.

The thesis formulated by Freud and Lévi-Strauss that animals do not serve as food but as food for thought and completely determine our metaphors about the world, becomes clear when we take a closer look at the idea of the so-called totemic operator. As a starting point, Lévi-Strauss chooses the notion of a species. A species assumes, however, its empirical realizations: species of seals, species of bear, species of eagle, etc. Particular species contain a further range of individual organisms, i.e. seals, bears, eagles, etc. Following this anatomical lead, each animal can be broken down into: head, neck, spatula, etc. Further - heads, necks, spatulas, etc. lend themselves to grouping into both the species (heads of seals, necks of seals, spatulas of seals, etc.), and "together" due to the kind of the body part, and not the species affiliation: all heads, all necks, all spatulas, etc. What comes into being from this operation is the head as such, neck as such, etc. Linking parts of the body in such a way will give us a general understanding of the organism - we reconstruct a model of the individual in its reconstructed integrity. Thus, we have outlined the skeleton of the so-called totemic operator, in which the poles of abstractions are the species and the specimen ${ }^{\mathbf{1 0}}$.

Thanks to the idea of the totemic operator it is easy to understand why Lévi-Strauss says that the dismemberment is supplemented by unification and the process of increasing the abstraction of thinking proves to be

8 Claude Lévi-Strauss, The Savage Mind, trans. George Weidenfeld (Letchworth, Hertfortshire: The Garden City Press Limited 1966).

9 Ibid., 214 .

10 Ibid., 119-121. 
simultaneously its concretization. Dismemberment of the notion of species into particular species, and in turn each species to its distinct specimen and each of those specimens to parts of the body and organs finally leads to a merger of concrete parts into abstract parts, and the abstract parts into an abstract specimen. The dismemberment then happens in the course of merger. If then I understand the basic intuition of Lévi-Strauss, he is trying to say that totemism, consisting in naturalization of the social world, is the reverse side of socializing the natural world, and the projection of nature on culture is as dangerous as projecting culture onto nature. Totemism is a procedure contrary to antropomorphization encountered in fairy tales: it is not the animals that represent the human characters and desires, but it is humans that represent animal powers and antagonisms between species.

It is here, however, where we encounter an added value, which, I believe, Freud will come across in Vienna when he will be analyzing the behaviors of his younger and older patients. From the point of view of biology, humans of the same race can be compared to the varieties within the same species. However, social life causes in nature a peculiar transformation because it stimulates every biological specimen to develop their personality (individuality). According to Lévi-Strauss, the notion of personality is not associated with the specimen as a consequence of variety, but rather with "types of varieties or of species, probably not found in nature and which could be termed «mono-individual»"11. Personality from this perspective is therefore a species containing only one specimen. It is the synthesis of parts of the body and physical-chemical processes in the form of an organism (and it is in this sense that it is a mono-individual species), but it also destroys the notion of a species, enriching the distinctive traits which allow for identification of a specimen of a particular species with an infinite set of traits determining the singleness of a specimen - an original synthesis of ideas and behaviors. In this sense, the notion of a specimen is beyond the genotype, it is a purely phenotypical notion.

I claim that Freud will find such an organic and mental construction, i.e. mono-individual species, on his Vienna couch. What do I have in mind? Well, I claim that little Hans and the even smaller Arpad, just like judge Schreber, Dora, and the "Rat Man" are cases of totemic projection of one's personality by the human of new democratic breeding so mercilessly unmasked and criticized by Nietzsche. It is not even the case of Hans identifying himself with horses and Arpad with chickens in order to become a horse or a chicken or to allow in this way the chicken or the horse to become something more than the horse or the chicken. The important issue is rather that Hans, Arpad,

11 Lévi-Strauss, The Savage Mind, 214. 
judge Schreber, Dora become a mono-individual species and that everything in their ontogenesis happens as if in Vienna or Paris in the beginning of the twentieth century each individual had its personality as its totem.

Yet what could this mean? Would it not mean that each individual wants to extrapolate one's being from within oneself? If my personality is a totem for myself, and a totem is a sign of my origin, would that not mean that Hans, Arpad, judge Schreber, Dora, and each of us experiences in this way their isolation from the world and from nature simultaneously? If I can find within me only the sources of my kinship, it means that apart from myself I have no relations, i.e. I am my own relative. Totem (my personality) is the symbol of my relative transcendence from the world of nature (the species of homo sapiens) but also from the world of culture (my father's family name). My given name constitutes my only family name. I become my own Father. Yet what role in this system do animals play, and in particular the names of the animals? Are animals - to paraphrase Freud once more - thanks to their unusual mobility, ability to fly, and other traits which cause astonishment and fear also in the twentieth and twenty-first century, suitable for being recognized as the carriers of souls which have abandoned their bodies?

\section{Names}

Lévi-Strauss contemplates the rules of giving names to various species of birds, dogs, cattle and horses. Lévi-Strauss simultaneously warns that giving names is never a task purely nominal and innocent, it may also indicate the naming (categorization) of oneself. Lévi-Strauss says nothing about the names of hens, just like he does not mention the name of spiders, bats, and finally worms, especially beetles. Certain species of animals are beyond the reach of interests of the author of Totemism (Totémisme aujourd'hui).

Species of birds, easier than other zoological classes, are given human names only because they can allow themselves to be similar to people, especially that they are so radically different. Song Thrush, Grey Kestrel, Laughing Gull, Peregrine Falcon, Marsh Tit, Mourning Dove - they are all expressions describing some purely human qualities. Are being in mourning or having an excessive sense of humor not characteristics of our personality? Birds covered in feathers have wings, are oviparous, and differ from the human society through their physical environment, in which they have the privilege of moving. Hence, because birds form a community independent from ours but which due to the independence proves to be homologous to humans, they gain human names and the temptation to anthropomorphize birds is a constant temptation of human thinking. Lévi-Strauss himself says that the relation of bird names to human names is the relation of the part to the whole 
(syntagmatic relation) only because birds constitute a metaphor of human society (paradigmatic relation).

Names of dogs are created in a completely different manner. Dogs do not form an independent society, but as domestic animals constitute a part of the human society (syntagmatic relation). That is why we appoint a different set of names for them: Butch, Coco, Stella, which almost exclusively sound like stage (theatrical) names form a parallel series to the names which are used every day, which means that they are metaphorical names (paradigmatic relation). Using the example of birds and dogs, Lévi-Strauss introduces the general conclusion: when the relation between species is understood as metonymic (the case of dogs) then the naming systems acquire a metaphorical character, and when the relation between species is understood as metaphorical (the case of birds) the relation between particular systems of naming acquires a metonymic character.

The situation of cattle is a different case entirely. The position of cattle is certainly metonymic in relation to the economic system of man, but is different from the position of dogs in that cattle are treated like objects and the dog like an individual. As a result, names which we give to cattle come from a series different than the names of birds or dogs; they are usually descriptive terms, alluding to the color of hide, posture, or temperament: Bessie, Carmella, Buttercup, Nellie, etc. Often the names have a metaphorical character and their goal is to suggest the servile character of the animal which is exploited in a given area of life. One can risk a statement that in our culture the culinary taboo includes dogs as a consequence of giving them names, which turns them into subjects, while the subordination of cattle to the culinary services leads to giving them names, which stress their complete objectification.

Finally, horses, especially exceptional horses, racehorses, whose social position is visibly separate from draft horses, are a peculiar culmination of the name nomenclature. Racehorses do not form an autonomous society like birds, nor do they form a society subjectively (dogs) or objectively (cattle) subordinate to human; they are rather a de-socialized condition of existence of a certain peculiar idle society: that which lives of the horse races and that which watches them. Names given to racehorses are selected with regard to particular regularities, subject to strict racial individualization, referring to the selected feature of a horse. It is impossible for two specimens to have the same name: Ocean, Azimuth, Telegraph, Elixir - creating names is free and nondescriptive. In this sense perhaps the names of the horses approach to the greatest extent the idea of a proper name. Lévi-Strauss states succinctly: if birds are metaphorical people and dogs - metonymical people, then cattle would be metonymical non-people and racehorses - metaphorical non-people. 
Let us ask a question now which at first sight may seem impossible: do animals have a personality and would Lévi-Strauss also have the audacity to say that they constitute a mono-individual species? Are a bird table, stud, doghouse, or henhouse places where everything happens as if each specimen had its own personality as a totem? Could animals - horses, lizards, spiders, cattle, dogs and birds, or even dorbeetles, just like Hans and Arpad, like judge Schreber, Dora, and Rat Man, recline on couch of Freud's, who tries to capture not so much the complexities of their unconscious psychic life, as he wants to understand: what digestive and sexual prohibition are they subject to?

\section{Domestication}

It seems that the answer to this tricky question is - no. Not every animal has its personality as a totem, although perhaps every animal, even the most primitive amoeba, can be endowed with a rich personality. Why do dogs and birds, horses and cattle not constitute totemic cultures? Well, this is caused mainly because of what Freud calls "disturbance". This disturbance is nothing but a process of domestication of animals, or, to use Lévi-Strauss's language, a "Neolithic paradox". "It was in Neolithic times that man's mastery of the great arts of civilization - of pottery, weaving, agriculture and the domestication of animals - became firmly established. No one today would any longer think of attributing these enormous advances to the fortuitous accumulation of a series of chance discoveries or believe them to have been revealed by the passive perception of certain natural phenomena"12. Certainly no one would think of attributing this Neolithic miracle to an accident, but some - many would think of explaining the Neolith by an accumulation of accidents. This accumulation of incidents is referred to today as structural causality, which means that the replacement of mechanical causality that works linearly in a straight sequence of producing effects, causality, in which each of the elements connected in binding the new structure is also its product or effect ${ }^{13}$.

Let us have a look at how this structural causality works in Freud. It seems that initially for Freud all sacrificial animals were sacred and that their meat was forbidden and could be consumed only during ceremonious events, in which the whole family participated. Killing such an animal meant the violation of a prohibition and was only allowed as an act meant to make the

12 Lévi-Strauss, The Savage Mind, 23.

13 See: L. Althusser, É. Balibar, Reading Capital, trans. Ben Brewster (London: New Left Books, 1970) http://www.marxists.org/reference/archive/althusser/1968/reading-capital/, Luis Althusser, "On Genesis", trans. Jason E. Smith, Décalages: Vol. 1: Iss. 2, http://scholar. oxy.edu/ decalages/vol1/iss2/11 
identification with a given species even stronger. Initially, man believed that God himself must be an animal or, in the later phase of evolution of religious feelings, believed at least that he developed from a totemic animal. I will repeat what my intuition tells me: Freud does not give a clear answer to the question about the reciprocal relations between God, the Father, and the Totemic Animal. Is the totemic animal a substitute for the killed father? Or, perhaps, the father is the substitute for the more primal totemic animal? After all, Freud also writes that in the scene of the sacrifice given to the Tribal God, the Father appears in a double role: as God and as the totemic sacrificial animal. It seems that the ontogenetic order leads Freud to a hypothesis about the primacy of the father over animals and gods, but the phylogenetic order gives primacy to the totem (animal) over gods and fathers. And there is no contradiction in this because we do not want to establish a linear series, which would order our events on a straight temporal axis, but to establish the rules of connecting dispersed events, seemingly distant from each other, into one formation, which speaks through its effect: domestication.

A milestone in relationships of the human and the animal was therefore the process of the domestication of animals. Domesticating animals and the emergence of cattle farming put an end to strict totemism of the early periods. Man's separation from the animal happens simultaneously with the fall of totemism, which happened as a result of the domestication of animals. Domestication of animals is the moment when all animals lose their initial holiness. They may only recover this holiness in the process of becoming something else, in the process of dislocation, displacement, which concerns both the mysteriousness of the human, and the totemism of the animal. This is the meaning of the famous formula of Gilles Deleuze and Felix Guattari - "We think and write for animals themselves. We become animal so that the animal also becomes something else. The agony of a rat or the slaughter of a calf remains present in thought not through pity but as the zone of exchange between man and animal in which something of one passes into the other"14. We must take a closer look at this zone of exchange, in which not only we become animals but above all the animals become something else, and therefore not us.

\section{Beetle}

Freud describes disruption as a process, which the child's ontogenetic history leads to the fact that the ambiguity of the rational world of adults moves

14 Gilles Deleuze, Félix. Guattari, What is Philosophy?, trans. Graham Burchell and Hugh Tomlinson (London: Verso, 2003), 109. 
to a position of familiarity of the animal kingdom, and the animals become a representation of the fears of the father. The infantile return to totemism is the return of Oedipus, who acquires both the structure of the child's phobias and totemic thinking. Kafka reverses the description and structure of this process thanks to which the son becomes the totem and the "mysteriousness" moves from the position of the animal to the position of the human. By writing The Metamorphosis (Die Verwandlung), Kafka offers us narration on the topic of the dedomestication of animals. It is not the child who suddenly starts to fear a certain species of animals and defend itself from the sight or touch of a specimen of this species, but the world of the adults suddenly starts to inspire fear in the child and makes it defend itself from its sight, as if from the attack of a malicious and dangerous species (an intruder).

Let us recall the reaction of Gregor Samsa's relatives when they saw him after the transformation into a horrible worm:

Gregor's mother - her hair, despite the chief clerk's presence, still disheveled from the night and right now standing on end - looked first with hands clasped together at his father, then took two steps towards Gregor and collapsed, surrounded by her outspread skirts, her face sunk and quite hidden in her breast. His father clenched his fist with a hostile expression, as if meaning to drive Gregor back into his room, but then he looked uncertainly round the living-room, covered his eyes with his hands, and wept so that his mighty breast shook ${ }^{15}$.

From the point of view of the family interactions, Kafka's The Metamorphosis is filled with actions of the mother to recover contact with her son, and the actions of the Father which have the goal of isolating his son. Gregor, however, contrary to little Hans analyzed by Freud or little Arpad analyzed by Ferenczi, failed to identify himself with the animal to such a degree as to start to walk like a worm and hunt like a worm, and never became a being which - according to Freud's wording - "bites his father". It is rather the father who struck his son by throwing at him the symbol of life - an apple: "(..) father had decided to bombard him. He had filled his pockets from the fruit-bowl on the sideboard and, without aiming very exactly for the moment, threw apple after apple"16. One of them literally got stuck in the stomach of the man-Gregorworm. Gregor became a worm so that the worm could become something else.

15 Franz Kafka, The Metamorphosis, trans. J. Crick, [in:] Franz Kafka, The Metamorphosis and Other Stories, (Oxford: Oxford University Press, 2009), 88. 
In his meticulous reading of The Metamorphosis, Vladimir Nabokov notes that Gregor transforms into an arthropod (Arthropoda) to which belong insects, spiders, myriapods and crustaceans ${ }^{17}$. Gregor Samsa is an insect, yet it is not clear what insect? Surely he is not, as commonly believed, a cockroach, because a cockroach is a flat insect with long legs, and Gregor is convex and has short legs, and more specifically: he has six short legs. Moreover, Gregor has strong jaws, which he uses to turn the key in the lock. In the German original, the cleaning-woman refers to Gregor as Mistkäfer, which means "dung-beetle". Nabokov claims that the hero of The Metamorphosis is not a dung-beetle but simply a plain beetle, who never discovered that he has wings under the hard back. The greatest hidden and never used ability of Gregor Samsa was his ability to fly. Perhaps if he had discovered it he could have become someone like Spiderman or Batman or even Birdy from William Wharton's famous novel.

Yet Nabokov's most important discovery is his recognition that Gregor, despite his transformation, still thinks in human categories and remains a prisoner of human cognitive categories, e.g. he believes that the man on all fours represents a beetle on six legs. Gregor Samsa's transformation is not complete, even more: it is only skin deep that Gregor becomes an animal and this transformation into an animal also concerns his speech, which with time ceases to be drawn into the circle of human affairs, and the brain, which initially even allows itself to be tempted with the fantasy about the bread and milk, but the beetle's stomach and his taste buds do not agree with mammal food. The beetle has a stocky body, strongly curved, 15-20 mm long, brown or black, shiny and feeding on animal manure, fresh dishes are not to his liking, he cannot even stand their smell.

Let us repeat Lévi-Strauss's fundamental thesis: when the relation between species is understood as metonymic (the case of dogs) then the naming systems acquire a metaphorical character, and when the relation between species is understood as metaphorical (the case of birds) the relation between particular systems of naming acquires a metonymical character. Therefore, the question is: what is the relation between insects (beetles) and the homo sapiens? Well, it has neither a metonymical character (beetles resembling only cockroaches are not part of the social system) nor metaphorical (they are also not a metaphor for social organization). I would venture a thesis that they are a negative part of social organization, namely that which is meant for unconditional extermination. Worms are metonymical non-people and due to that, they can take non-human, metaphorical, negative names.

17 Vladimir Nabokov, Lecture on "The Metamorphosis", 2011, http://www.kafka.org/index .php?id $=191,209,0,0,1,0$ 
Probably the first person who truthfully and accurately diagnosed Samsa's problem, or rather the problem of the clan of worms, was his sister from whom we hear the following words addressed to the family (Father):

'It has to go', cried the sister, 'that is the only way, father. You must just try to get rid of the thought that it is Gregor. Our real misfortune is that we have believed it for so long. But how can it be Gregor? If it were Gregor, he would have understood long ago that it's not possible for human beings to live with a beast like that, and he would have left of his own free will. We wouldn't have a brother then, but we would be able to go on living, and honor his memory. But as it is, this beast is pursuing us and driving away our lodgers; it obviously wants to take over the entire apartment and put us out to sleep on the street ${ }^{\mathbf{1 8}}$.

In principle, this statement contains all the necessary diagnostic elements, even a draft of a possible therapy. The worm has to be exterminated so that his name can be retained.

Let us recall that the sister is the person who feeds Gregor during the transformation. Yet the sister is not aware that Gregor retained his human heart, human sensitivity, tact, sense of shame and tragic pride. It is not just the fact that Gregor is called here a "beast", which pesters the family and tries to adjust the territory of the clan's existence to his own existential imperatives; neither is it about the fact that the family resents Gregor, who has undergone the transformation into a worm and shed his armor of a working clerk. And let us just recall that the plot of The Metamorphosis suggests that Gregor not only supported the whole family, but also found for it the apartment in which it currently resides. It is rather that by taking the form of an animal, Gregor still uses his proper name and feigns kinship with the clan, to which he physiologically no longer belongs. In fact, the sole solution is contained in the short command: It has to go. Gregor has to disappear not because he is useless, but because in order to retain the memory about kinship the worm has to disappear to retain the memory of a human: his name.

The main thesis emerging from the reading of The Metamorphosis is Nabokov's statement: "Gregor is a human being in an insect's disguise; his family are insects disguised as people. With Gregor's death their insect souls are suddenly aware that they are free to enjoy themselves"19. This thesis would explain why Gregor sees his only hope in his sister. Beetles reproduce by

18 Kafka, The Metamorphosis, 69.

19 Nabokov, Lecture on "The Metamorphosis". 
digging underground tunnels with brood chambers filled with animal dung. In each chamber the female lays one egg. The larvae hatch in the spring of the next year and the adult specimens appear in the early summer. Gregor prepares in his room the territory for his sister, i.e. he creates corridors with brood chambers in which she could lay an egg. Gregor becomes one of the animals which, as Freud phrased it, "fitted by their extreme mobility, their flight through the air, and by other characteristics" cause astonishment and fear, suitable to be qualified as the host for the souls, which have left the body. Gregor is the bearer of souls, which have left the bodies of his family - his father, mother, and finally, sister. In a nutshell, one can say that Gregor becomes the totem of the Samsa family. This is why Kafka writes: "The family itself ate in the kitchen" 20 . The family eats in isolation from Gregor, alone, because totemism, as we have determined, is the regulator of relations of kinship and consumption. The beetle/totem draws not only the lines of kinship, but also the line of the sole culinary object, which constitutes a taboo.

Towards the end of the third part of The Metamorphosis, hearing the music made by his sister he is so enchanted, bewildered, delighted that he dares to enter the family (public) room. In this scene Kafka asks an excellent question: "Was he a beast, that music should move him like this?"21. It is the fact that music moved him and not the spoken word that is the best proof that Gregor has become something else than a human. Yet Gregor is a totemic animal, which means that Gregor has never been an ordinary animal, although his sister and his family were insects dressed as humans. Kafka writes about this moment of absolute elation of Gregor the beetle in the following manner:

He resolved to advance right up to his sister, pluck her by the skirt to intimate that he was asking her to come with her violin into his room, for no one here was rewarding her playing as he would reward it. He wouldn't let her out of his room ever again, at least not while he was alive; his terrifying figure should be useful to him for the first time; he would post himself by all the doors of his room at once and go hissing to meet his attackers ${ }^{22}$.

Kafka could not have stated it more clearly: Gregor's only object of desire is his sister. Gregor Samsa has turned into an animal, a beetle, a worm, to take the form equal to the wormish nature of his sister, which would allow him to become the sexual partner of the only object, which human culture has denied

\footnotetext{
20 Kafka, The Metamorphosis, 65.

21 Ibid., 66.

22 Ibid., 67.
} 
him. It is not the Father, not the Mother, who is the main object structuring Kafka's novella, but the Sister.

\section{Reproduction: Party of Life}

Gilles Deleuze and Félix Guattari say that in Kafka's The Metamorphosis there appears a distinction between two states (forms) of desire. The first form appears when Gregor "presses himself against" the portrait of a woman in fur, turning his head towards the door in a desperate attempt to stop something in the room, although it has already been emptied. Gregor tries to link desire with memory, with picture, with the representational register. It is a regressive form, which will never allow him to fully become an animal. Kafka describes the behavior of the hero thus:

[...] he really had no idea what to rescue first, when, hanging on the wall, which was otherwise bare, he was struck by the picture of the lady dressed in nothing but fur. He crawled up to it hurriedly and pressed himself against the glass, which held him fast and did his burning stomach good. This picture at least, which Gregor now covered completely, no one would take away from him - that was certain ${ }^{23}$.

The picture of the woman in fur does Samsa's burning stomach good. It is not the belly of a glutton, but the belly of conception, a symbol of the umbilical cord linking the son with his mother. In this sense, Gregor pressed against the picture is still Oedipus, which means that he is still a man. Greta, seeing Gregor's obstinacy, has to capitulate in her defense of the picture. "He was sitting on his picture and he wasn't giving it up. He would rather make a leap for Grete's face"24. Gregor Samsa would rather deprive Greta of sight, because this is what is meant by "leap[ing] for Grete's face", than to be deprived of the picture cooling his burning stomach.

The second form of desire appears when Gregor abandons the territory of his room in response to the sound of the vibrating violin coming from the adjacent room, and when in desperation he tries to kiss the throat of his sister, sticking to it like a ribbon or collar25. This time Gregor is not pressed against the "cooling" picture, but to the warmth of his sister's neck. Here the

23 lbid., 55-56.

24 Ibid., 56 .

25 Gilles Deleuze, Félix. Guattari, Kafka:Toward a Minor Literature. Minneapolis, trans. Dana Polan, (Minneapolis London: University of Minnesota, 1975), 5. 
worm becomes a vampire and ceases to be a human. This a progressive form of desire, a form triggered by hearing, in which everything is seduction, and therefore music.

Meanwhile Gregor's sister had got over the bemused state she had fallen into after the sudden interruption of her playing, and, after she had held violin and bow in her drooping hands for a while and then gone on looking at her music as if she were still playing, she suddenly pulled herself together, put the instrument into her mother's lap [...] and dashed into the next room $[\ldots]^{26}$.

In this description, Samsa's sister is the picture of a woman after the sexual intercourse, she is the state of post-climax, post-copulation. Music and voice in Kafka's works always play an important role, suffice it to recall his short story entitled Josephine the Singer, or the Mouse Folk, which tells the story of a cult mouse prima donna Josephine ${ }^{27}$. Josephine not only sings, but also whistles by blowing on the last hole of a wind instrument, so that it emits the highest possible tone. Josephine, like Gregor's sister playing the violin, urges the males to copulate, to reproduce.

Deleuze and Guattari write that they deeply believe in Kafka's politics, which does not have imaginary or symbolic character, just like they believe in Kafka's machines which are neither a phantasm nor a simple structure. Finally, they believe in Kafka's sense of experimenter, which is not subject to rules of interpretation and a simple process of giving meaning, but which is rather based on experience. But even they start to read Kafka from the figure of Baroque and an exaggerated, reconstructed Oedipus. In this sense, for Deleuze and Guattari The Metamorphosis is an exemplary story on the subject of re-Oedipalization, which means that the process of Gregor's deterritorialization through his turning-into-animal will find its end in the picture. Gregor does not dare to become a total animal. To satisfy his brother, his sister wants to empty the whole room, but Gregor refuses to allow the portrait of the woman in fur to be removed and holds on to the portrait as his last picture. Probably Gregor would rather become a dog, an animal which is Oedipal by definition, an animal very close to Kafka, if only because he writes Investigations of a Dog (Forschungen eines Hundes). According to Lévi-Strauss, dogs are metonymical people and Gregor is supposed to become a worm. Worms are

26 Kafka, The Metamorphosis, 67.

27 Franz Kafka, "Josephine the Singer, or the Mouse Folk" [in:] The Metamorphosis and Other Stories, trans. Donna Freed (New York: Barnes \& Noble, 1996). 
metonymical non-people and due to that, they can take non-human, metaphorical (negative) names.

Yet, we are not interested here in the question: what is the literature of the minority? We are not interested in Kafka's politics, just like we are not interested in his machines. We are not even interested in the answer to the question: what is the montage in Kafka's work? We are interested in a certain disruption, which is a result of domestication, i.e. initiating human raising and negative breeding. This initiation of raising and negative breeding results in reproduction of confused species, hybrids of our humanity with other species, unaffiliated with people. Let us look at some specimens of these monoindividual species, which wear our personality as a totem and start to populate planet Earth. Let us look at the effects of this negative breeding, reversed domestication, dedomestication initiated by Kafka's breeding.

Spider-Man is a species related to Freud's little Hans (horse-man) and Ferenczi's little Arpad (chicken-man). Peter Parker became an orphan when he was six, both his parents (in the Marvel Comics version) died in an airline catastrophe. During a presentation of waste handling from a nuclear laboratory, a spider gets in the field of the particle accelerator and becomes irradiated. With his arm bitten by the spider, Peter acquires some of his wonderful powers of spider-man. Peter's attitude to the spider is the same as Arpad's attitude towards the chicken, which pecked at his penis during urination. Spiders are arthropods belonging to the same family as Gregor. To somewhat exaggerate: the spider which bit Peter Parker is the transformed Gregor Samsa, who was supposed to be exterminated but survived with other waste materials.

Yet, let us look at another unclean, mono-individual species. Batman is Bruce Wayne - a calm, happy child of a couple of billionaires. We often hear that Bruce was not spoiled, his parents, despite the fortune which they possessed, were not snobs. Contrary to Peter Parker, Bruce experienced the pre-Oedipal period. One day, the family (father-mother-son) went together to cinema to see the movie Zorro. After the screening, they went home when suddenly, from around the corner, a bandit appeared demanding money and jewelry, and when the Waynes resisted he killed them without remorse as the boy watched. Bruce vowed vengeance against everything that violates the law. Yet the law is nothing but the name of the Father. Bruce becomes the incarnation of the voice of the Father, and so the executor of the voice of the Law. As a result, Bruce resembles little Hans more than little Arpad. Only the 2005 film version, entitled Batman Begins requires us to believe that Bruce's marking with the bats is a derivative of the childhood trauma that resulted from being trapped in an underground cave under the well, where he was bitten by bats like Arpad was pecked by chickens. 
To paraphrase Lévi-Strauss, one can risk the following typology: if birds are metaphorical people (William Wharton's Birdy) and spiders (Spider-Man/ Peter Parker) - metonymical people, then worms (Beetle/Gregor Samsa) would be metonymical non-people and bats (Batman/Bruce Wayne) - metaphorical non-people. Does anything link this formation of species, confused and unassociated? And yet this formation is still not complete, because what lacks is for instance elephant-man filmed by David Lynch - Joseph Merrick who was born in 1862 in Victorian England, only to discover an animal within himself when he was three years old: Symptoms (tumors, skin deformations) appearing on his body require him to play the role of an elephant-man in a circus. I repeat the question once more: is there a common trait linking the aforementioned mono-individual species, cross-species hybrids, confused, unclean?

We return here to the hypothesis and diagnosis of Nietzsche who announced in Ecce Homo the coming of a new party of life "which would take up the greatest of all tasks, the higher breeding of mankind, including the pitiless annihilation of all degenerates and parasites, will make possible again that excess of life on earth from which the Dionysian condition must rise again as well. I give promise of a trag ic age: the highest art in life affirmation, the tragedy, will be reborn when mankind has put behind it the consciousness of the hardest but most necessary wars without suffering from it..." ${ }^{\mathbf{2 8}}$ We are not yet ready to tame this new party of life, however, we are ready to accept a disturbance - a new world, world full of dedomestication, in which fear is aroused by a named animal, which is neither a human nor a god.

28 F. Nietzsche, Ecce Homo: How One Becomes What One Is \& The Antichrist: A Curse on Christianity, trans. Thomas Wayne (New York: Algora Publishing, 2004), 52. 